\title{
Professional activities of a social teacher and a tutor in psychological and pedagogical support of the adolescents development in the space of informal associations
}

\author{
F.O. Semenova ${ }^{1 *}, A . S$. Balyk $^{2}$, and M.M. Ebzeev $^{3}$ \\ ${ }^{1}$ Umar Aliev Karachai-Cherkess State University, Karachaevsk, Russia \\ ${ }^{2}$ Nevinnomyssky State Humanitarian Institution, Nevinnomyssk, Russia \\ ${ }^{3}$ Umar Aliev Karachai-Cherkess State University, Karachaevsk, Russia
}

\begin{abstract}
The social transformations taking place in Russia influenced by socio-economic changes have led to a revision of many socio-pedagogical guidelines. Today the school as a leading social institution cannot solve educational problems effectively without interaction with various children's and youth public associations, which play an important role in the socialization of the younger generation, meeting its needs, selfrealization and self-development. Young people feel a especial need for the activities of such associations because of their age characteristics young people are looking for recognition of their personality, dignity and respect for themselves. However, the modern youth movement in Russia is represented not only by organized structures, but also by an informal youth initiative. The importance of informal associations for the socialization of the younger generation is acquiring special attention today. Practice shows that the process of socialization of the younger generation is carried out mainly spontaneously, without proper coordination of the educational influences of various socio-pedagogical systems.
\end{abstract}

\section{A problem statement}

Now when domestic science is not limited by ideological dogmas, when there are social teachers and tutors in general educational institutions who can work in this field, pedagogical analysis have the possibility of a more objective approach to assessing modern youth culture and resources for solving important issues with the socialization of student youth in informal youth associations [1].

The problem of the research is conditioned by a number of contradictions between: the active desire of student youth for self-realization in creativity and the lack of the necessary conditions and opportunities; social requirements for the social and normative behavior of student youth in creative informal associations and the real level of its formation; the

\footnotetext{
*Corresponding author: prof-ped.gpa@mail.ru
} 
objective needs of the subjects of socializing influence in the scientific and methodological support for solving the problem of socialization of student youth in creative informal associations and insufficient development of methodological approaches and guidelines for preventive and correctional work.

\subsection{The objective of the work}

Purpose of the work is to analyze the features of the professional activity of a social teacher and tutor in psychological and pedagogical support of the personal development of student youth in informal associations in the context of a general educational organization.

\section{Results of the research}

Now sufficient experience has been accumulated in the theory and practice of the psychological and pedagogical sciences and it can become the basis for solving the problems of the formation of socially normative behavior of student youth in creative informal associations.

The important role of informal children's and youth associations as a condition for the socialization of a person is reflected in the works of Russian psychologists and teachers: Anisimova I.A. Gordon, E. Prokopenko E.V. Wittenberg, Renee Butler, Ian and Gwenda Roberts [2-7].

The activitiy of modern children's and youth associations in the Russian Federation solves internal organizational problems and tasks and does not have a significant impact on the state youth policy. We explain it by the fact that the activities of informal creative children's and youth associations, schools, out-of-school institutions, government organizations and institutions should be common [8].

An important role in this process in modern conditions is assigned to social teachers and tutors.

A social educator and a tutor act as initiators, organizers and active participants in cooperative activities with students and adults. Because of their professional training and activities, they act as mentors who will accompany a young person for several years, carry out social patronage, trace the process of the formation of moral universal values in society, act as a social therapist who helps to anticipate and resolve conflict situations, and also to get out of conflicts without psychological trauma and destruction $[9,10]$

The dynamics of modern socio-political and economic life leads to an acceleration of the process of socialization of the personality of young people, the formation of social relations based on the protection of the individual, the choice of new ways of exchanging spiritual and social values. In this sense children's and youth organizations have their advantage over the school, since the school is a state institution, and in its political, ideological assessments it inevitably adheres to the official line. Children's and youth organizations function not in the state, but in society, they are free to educate a free person.

In pedagogical science, there are the following forms of interaction between a social teacher and a tutor in youth informal associations:

- partnership, establishing relations in order to define tasks and their further joint implementation;

- leadership, when a social educator or tutor is a leader among members of one or more organizations and has experience in leadership and organization of social activities;

- coordination is possible as an option for coordinating the activities of several organizations (institutions, institutions, etc.) or a common project (program) in case of recognition of the right to such a role; 
- mediation is the activities of a social teacher and tutor aimed at establishing contacts, exchanging organizational experience with other organizations, government agencies, educational institutions, etc;

- mentoring is the transfer of experience in organizing social activities to a children's or youth association and assistance in translating this experience into the practice of the association [11]

Practice shows that a modern general education school in extracurricular activities, the socialization of student youth is carried out mainly spontaneously, without proper coordination of the educational influences of various socio-pedagogical systems. In reality some informal youth groups solve problems of social justice and equality outside the law. Others think that withdrawing from society is the best way to combat public hypocrisy and other negative phenomena.

Russian teachers Batyscheva I.V., Shipilova E.P. and others propose to act in such way: diagnostics (study, analysis of the factors of upbringing, the conditions that caused them, determination of ways and means of neutralizing negative tendencies and actualizing the positive in the behavior of young people);

planning and defining the content of work (developing a plan of interaction, determining the place and role of each in this process);

- pedagogical activity (implementing plans for re-educating a specific person with the involvement of parents, classmates, teachers, etc.) [8].

An important issue in the interaction of student youth with social educators and tutors is the issue of trust, respect and readiness to communicate. It is closely related to the issue of the image of a teacher, educator, social teacher and tutor. The image of a teacher has been repeatedly considered as an object of research for teachers, psychologists, and political scientists. Zaitseva I.I. says the image of the teacher should correspond to the main trends in fashion, i.e. it must be relevant, modern. However, clothing items should not express a favorable attitude towards any informal group or subculture [12].

The ability to tune a person to oneself by words and actions is a necessary component of the image. It is also important for teachers to use methods of giving information adequate for youth associations, receiving answers, establishing relationships, exchanging impressions, this is the so-called stylized communication. Clothing, manners, methods of communication should inspire confidence, a sense of security, a sense of decency and competence.

The "position of acceptance" as a direction of work with young students of informal associations is widely represented in the psychological literature. So, Voronov V.N. drew points to the fact that social teachers need to develop a new, youth-oriented concept of social and pedagogical work with young students, which should be based on: the principle of integrating the efforts of all interested subjects of socialization and educational influences, and the fact of recognition of youth associations as a subject of socialization of the young generation". Accordingly, in social pedagogy and the practice of social work, the concept of the model of "Open work with youth" became as the position of accepting informal youth associations as a social reality, groups performing communicative functions [13].

A feature of the new approach to working with youth is the activity of social workers and teachers at the place of residence and leisure of student youth. In the context of this direction, the movement for the creation of leisure infrastructure has become widespread. New houses of culture, equipped with everything necessary for both interesting activities and meaningful leisure, became the basis. As a result, direct work with youth associations, due to its diversity, has become more differentiated and encompassed both social and pedagogical assistance to the collectives of associations (getting into contact with members of the formation, developing a procedure for gaining their trust, identifying the motivation 
for youth participation in these associations), and assistance in solving the individual problems of each member of the youth association.

Conceptual rationale for the application of the basic principles of the development of the creative potential of youth informal associations are presented in the theory of creative self-development and the theory of socio-cultural activity: the principle of universality and accessibility; amateur performances; consistency and purposefulness; socio-cultural continuity; creative self-development and self-realization; pedagogical support [14]

The strategy of providing an alternative presupposes knowledge of the basic needs of people by specialists working with young people, as well as the determination, using diagnostics, of motives that are relevant for a specific sociocultural situation - a district, city, social group.

In particular, scientists propose to involve students in productive, creative forms of activity. So, for example, N.A. Gekman suggests using the natural attraction of punks to translate lyrics to create a language learning club; aspiration of hip-hoppers to versification, dancing and drawing to create correspondence of poetry, choreographic and art clubs and the like. N.A. Gekman sees the main way of working with informal youth associations like creating a social and educational environment (club) based on those age needs for communication, self-affirmation, which generate street, yard companies and informal youth associations [15].

According to MA Larkin, the creation of a club association on the basis of youth subcultural practices contributes to accepting of their own personality by young people; mastering various options for self-presentation in a socially approving form (organizing experimentation and self-expression by constructing a kind of "carnival" venues, where during various games, competitions, concerts, participants have the opportunity to selfactualize) other subcultures) [16].

Researchers note that diagnostics plays an important role in working with informal youth associations. For example, psychological diagnostics develops the theory, principles and tools for assessing and measuring individual psychological characteristics of a person; social diagnostic develops a set of methods by which the level of social well-being / distress and social health of a certain social environment (micro-society) is determined, pedagogical diagnostics studies the principles and methods of recognizing and establishing signs that characterize the normal or deviating from the norms of the pedagogical process (Leus E., Soloviev A.G. and others). The study of creative informal associations is most consistent with the integrated use of all three types of diagnostics. After all, the reasons for the manifestations of abnormal behavior can be both the individual characteristics of young people and the social environment.

In adolescence, reflexive competence and the formation of conflictological competence are important. These competencies are formed in future specialists in the process of studying at the university $[17,18]$.

The quantitative indicators that need to be established during the diagnosis are age, social and gender composition of the group, duration of existence, frequency of meetings of members. Qualitative indicators are readiness for joint activities, the nature, purpose, motives and focus of activities, the level of group development, responsibility for group activities, internal structure, collectivity, conflict, types of communication and relationships, requests and ways to satisfy them, norms and values, possibly the criminal past of the members.

Social practice and the results of scientific research in this area (Tabachnikova A.V., Sologub N.N., etc.) make it possible to identify methods that a social teacher, tutor, educator can use to diagnose informal youth associations. Diagnostic methods are selected depending on their functional action in the process of determining the level of formation of social normative behavior. In particular, the following methods are widely used: 
observation, questioning, conversation, interviews, analysis of activity products, certification, social biography, parametric method, forecasting method, diagnostics of the social environment, testing of personality traits, individual typological qualities and properties, interaction in different spheres of life and etc $[19,20]$.

These methods will make it possible to establish how the interests and needs of the group are changing, how stable it is and what its prospects are, to study (identify) the group leader, since it is the leader who often determines the direction of the informal group, its openness to external contacts, the possibility of reorientation, correction of attitudes and activities [4]. An important direction of diagnostics is the study of the motivational sphere of student youth of creative informal associations: identifying the level of formation of the system of value orientations; the level of aspiration of student youth of creative informal associations to imitate the social norms of behavior; the degree of satisfaction with basic needs; as well as the content of motives, their orientation and stability.

The next stage of psychological and pedagogical diagnostics involves the study and identification of the level of understanding the creative informal associations of the very subject of social normative behavior, awareness of how important norms are at the level of interaction with an individual, group, society. Diagnostics allows you to identify and determine the degree of understanding of the essence of the concept "Socially normative behavior"; level of knowledge of ethical norms, ethical aspects of behavior; the level of knowledge about the ways of manifestation of normative behavior in relationships; the degree of operating with moral judgments. So, in modern conditions, in the issue of socialization of student youth, the leading role belongs to social teachers and tutors, who cooperate with other subjects of socializing influence and directly with youth informal associations, they can create conditions for the development of a leadership asset; help in determining the main goals of the activity, prevent difficulties; to draw the attention of state and local authorities to solving the problems of creative informal youth associations; to establish interaction of informal youth associations with other social groups; organize the activities of informal youth associations, which were aimed at helping peers and other people (you need to organize preparation for such activities: give several options for choosing future activities - for example, charity concerts, fundraising for those who need help, etc.); do pedagogical correction of social behavior and social connections, contributing to the optimal resolution of conflicts; carry out the prevention of antisocial behavior, which is ensured by working with every young person who is a member of informal youth associations.

To identify the social activity of schoolchildren in informal youth associations, we carried out empirical work in Gymnasium No. 17 in Cherkessk. The respondents were 148 students aged 12-17. A questionnaire "Assessment of the relationship of adolescents with the group", a survey and interviews were conducted with the respondents.

As the socialization of the personality of a teenager, young man largely depends on the nature of the interpersonal perception of the informal group, as well as on many factors, such as social attitudes, past experience, the nature of interpersonal relationships, the degree of awareness of each other, etc. In order to identify the features of the interaction of student youth with an informal group, a questionnaire "Assessment of the attitude of a teenager to an informal group" was compiled.

This technique lets identify the types of perception by an individual of a group through an assessment of the role of the group in the individual activity of the perceiver. As a result of the application of this technique, three types are identified: the first type is when the respondent perceives the group as an obstacle to his activities or treats it neutrally; the second type is when the respondent perceives the group as a means that contributes to the achievement of certain individual goals; the third type is when the respondent perceives the group as an independent value. The following methods were also used: Schwartz's value 
questionnaire (CO); diagnostics of the level of moral upbringing and moral self-assessment by the method of M.I. Shilova; test "Attitude to moral norms of behavior" (E.N. Proshitskaya S.S. Grinshpun); "The method of assessing the moral development of the individual" (I.V. Mashchenko, N.N. Protko); Rokeach's "Value Orientations" method [21]. The results were calculated with the use of statistical processing methods, systematized and interpreted. In general, a positive dynamics of changes in quantitative characteristics and levels of formation of social activity of student youth of informals was revealed, in particular, the sufficient level of formation of social activity of student youth of informals increased by $21.0 \%$, the average level of formation of social activity of student youth of informals decreased by $10.0 \%$, and the low level of formation of social activity among nonformal students decreased by $13.0 \%$. The results of the study made it possible to state the achievement of the research goal, since it was revealed that it is the work of a social teacher and a tutor on psychological and pedagogical support for the development of the personality of student youth in informal associations that makes it possible to increase the social activity of student youth.

\section{Conclusions}

Having studied the features of the work of a social teacher, a tutor with informal youth associations in the context of a general educational organization, we came to the conclusions that social teachers and tutors, in contrast to educators and class teachers, are largely informed about the presence, specificity and development trends of modern informal youth associations. At the same time, the overwhelming majority notes the negative nature of the influence of informal associations on the socialization of student youth, since such associations act as a source for the spread of deviant behavior patterns and the substitution of the concepts of approved behavior from social to asocial. Psychological and pedagogical science regards an informal association as an organization characterized by a high degree of cohesion, a personal nature of communication, an unclear purpose of group activity and informal control based on traditions and depending on the degree of awareness of group membership. The main reasons for youth joining informal youth associations are the need for communication, the desire to express themselves, to assert themselves, family problems, lack of conditions for organized leisure, etc. Therefore, the main functions of informal youth associations are: educational, self-determination, selfaffirmation, communicative, information and entertainment.

According to the results of the analysis of psychological, pedagogical and sociopedagogical works, a typology of informal youth associations was determined, the main criterion of which is the orientation of adolescents' activities. Informal youth associations of adolescents are classified depending on the type of interaction between the individual and the group through an analysis of the nature of their individual interaction and the level of perception of the group by the individual as a value.

Analysis of the research results allows us to conclude that it is necessary to carry out social and pedagogical work with children in informal youth associations.

Experimental and experimental work in Gymnasium No. 17 in Cherkessk showed the effectiveness of social and pedagogical work with children in informal youth associations. In general, a positive dynamics of changes in quantitative characteristics and levels of formation of social activity of informal adolescents was revealed, in particular, the sufficient level of formation of social activity of adolescents of informals increased by $21.0 \%$, the average level of formation of social activity of adolescents of informals decreased by $10.0 \%$ and the low level of formation of the social activity of informal adolescents decreased by $13 \%$. 
An analysis of the real state of the spread of the informal youth movement allows us to state the predominantly low level of social activity of informal adolescents. So it is important to develop and implement new content, forms and methods of social work with adolescents in informal youth associations.

\section{References}

1. S.I. Askhakov, Experience of social work in various spheres of life, 231 (2019)

2. I.A. Anisimova, Prevention of destructive behavioral deviations of older adolescents from informal youth associations, Collection of articles of the XXXIII international scientific and practical conference, 191-196 (2020)

3. E. Gordon, Centuries of tutoring: the history of alternative education in America and Western Europe, 347 (2008)

4. E.V. Prokopenko, Informal youth associations and their impact on adolescents, Alley of Science, 3, 591-594 (2019)

5. R. Wittenberg, Opportunities in Social Work Careers, 170 (2003)

6. I. Butler, R. Gwenda, Social Work with Children and Families: Getting into Practice, 366 (2004)

7. N.Yu. Lebedeva, O.A. Pryalochnikova, E.A. Tsirulnikova, Manifestations of personality subjectivity in informal youth associations of various types, In the book: a collection of articles of the ninth international scientific and practical Internet conference, 228-232 (2017)

8. I.V. Batyscheva, E.P. Shipilova, Informal youth associations, their impact on juvenile delinquenc, In the collection: materials of the 1st All-Russian scientific and practical conference, 12-15 (2016)

9. F.O. Semenova, S.N. Bostanova, M.K. Tetuyeva, L.A. Apanasyuk, A.E. Ilyin, N.G. Atayanz, Formation peculiarities of students readiness to social self-determination, Man in India, 97, 3, 77-87 (2017)

10. M.S. Maksimova, Features of work with informal youth associations in the professional activity of a specialist in working with youth, My professional career, 5, 254-260 (2019)

11. D.V. Alzhev, Social pedagogy, 127 (2019)

12. I.A. Zaitseva, Informal youth associations as an object of social work, 242 (2019)

13. V.N. Voronov, Development of the youth movement and informal youth associations in Russia, Science. Society. Defense, 2(5), 4 (2015)

14. A.V. Tabachnikova, N.N. Sologub, Youth subculture: problems and ways to solve them, In the collection: The contribution of young scientists to the innovative development of the agro-industrial complex of Russia. Collection of articles of the All-Russian scientific-practical conference of young scientists, 340-343 (2020)

15. N.A. Gekman, Pedagogical approach to the development of the leadership potential of members of youth informal associations, Innovative technologies in the humanitarian sphere, 16-19 (2020)

16. M.A. Larkin, Youth informal groups (associations) of criminal orientation as a manifestation of counterculture, In the collection: Legal culture in modern society. Collection of scientific articles of the II International Scientific and Practical Conference. Scientific electronic text edition, 514-517 (2019) 
17. F. Semenova, F. Salpagarova, The influence of reflection on the process of personality socialization in adolescence. Published online: 22 November 2019. DOI: https://doi.org/10.1051/shsconf/20197008035 https://www.shsconferences.org/articles/shsconf/abs/2019/11/shsconf_ictdpp2018_08035/shsconf_ictd pp2018_08035.html

18. M.M. Ebzeev, F.O. Semenova, Formation of conflictological competence of a future specialist in the process of studying at a university, P.F. Lesgaft, 10(92), 174-178 (2012)

19. A.S. Balyk, Basic components of personal maturity, European Social Science Journal, 10(49), 409-417 (2014)

20. E.V. Leus, A.G. Soloviev, Socio-psychological aspects of the influence of informal adolescent and youth associations on the formation of personality, Youth as a marginal group, 53-66 (2016)

21. A.A. Karelin, Great encyclopedia of psychological tests, 416 (2009) 